\title{
Formation of Gradient Structure in Rails at Long-Term Operation
}

\author{
Anton Yuriev ${ }^{a}$ (D), Vasiliy Kormyshev ${ }^{b}$ (D), Victor Gromov ${ }^{b *}$ (D), Yurii Ivanov ${ }^{c}$ (D), Alexander Semin ${ }^{b}$ (1) \\ aJSC 'Evraz-West-Siberian Metallurgical Combine', 654043, Kosmicheskoe shosse, 19, \\ Novokuznetsk, Russia \\ ${ }^{b}$ Siberian State Industrial University,654007, 42 Kirov Street, Novokuznetsk, Russia \\ 'Institute of High Current Electronics SB RAS,634055, 2/3 Akademicheskii Ave., Tomsk, Russia
}

Received: June 17, 2020; Revised: October 20, 2020; Accepted: October 23, 2020.

\begin{abstract}
It has been shown by the methods of physical material science that long-term operation of rails is accompanied by the formation of the gradient structural constituents consisting in the regular change in relative content of lamellar pearlite, fractured pearlite and structure of ferrite-carbide mixture in cross-selection of rail head. As the distance to the surface of rails increases the relative content of metal volume with the structure of lamellar pearlite decreases and that with the structure of fractured pearlite and ferrite-carbide mixture increases. It has been established that the characteristic feature of ferrite-carbide mixture structure is a nanodimentional range of grains, subgrains and particles of the carbide phase forming it. The dimension of grains and subgrains forming the given type of structure varies within the limits of 40-70 $\mathrm{nm}$. The size of carbide phase particles located along the boundaries of grains and subgrains varies within the limits of 8-20 nm.
\end{abstract}

Keywords: gradient structure, transmission electron microscopy (TEM), carbides, nanostructured materials, pearlitic steels.

\section{Introduction}

The processes of formation and evolution of structural phase states and properties of rail surface layers in long-term operation is a complex system of interrelated scientific and technical problems. The improvement of differentiated quenching modes of long rails for the formation of high operational properties should be based on the knowledge of mechanisms of structural phase changes in cross-section of rails at their long operation. The revealing of these mechanisms is possible only in analyzing the regularities of evolution of fine structure parameters and estimating the contributions of structural constituents and defective substructure into the hardening of rails at long-term operation (passed tonnage more than $100 \mathrm{mln}$. tons). The gradient materials are called to be those whose typical feature is the regularly changing characteristics of elemental and phase composition, defective substructure state ${ }^{1}$ in the bulk and/or on the surface of a product. Gradient structural phase state may be formed in a material both as a result of self-organization of defective substructure, elemental and phase composition initiated by different thermo-power effects and be purposefully designed $^{1-4}$. The majority of gradient structures used in technology are artificial. Gradient structures are divided into two large classes depending on their location in a material volume: bulk and surface. The number of types of surface gradient structures is considerably larger. To these belong the following structures:

- formed as a result of ion implantation;

- $\quad$ appeared in friction or oxidation;

*e-mail: gromov@physics.sibsiu.ru
- $\quad$ formed as a result of surface saturation with different elements of penetration (cementation, nitriding, boriding, etc) or elements of substitution (gilding, silver plating, chromium plating, nickel plating, etc);

- $\quad$ emerged as a result of surface cold hardening or other methods of surface mechanical hardening;

- formed as a result of ultrasonic machining of surface;

- meeting the requirements of different types of single- and multi-layer coatings;

- $\quad$ appeared after of shock waves, electron beams, powerful ion beams, intensive plasma flows;

- $\quad$ emerged in consequence of laser or microwave radiation, as well as in plasma of gas discharge;

It is apparent that at severe deformation effect being realized at long operation the different processes (recrystallization, relaxation processes, phase transitions, decomposition and formation of phases, amorphization, etc) leading to the evolution of structural phase states and being accompanied by the formation of structural phase gradients ${ }^{5-13}$ may take place.

It is proved that wear defects are initially formed in the surface layers, in this case the beginning of the permanent wear coincides with the accumulation of definite level of plastic deformation ${ }^{14-19}$. In long-term operation the irregular high value of wear is observed on the surface. The knowledge of regularities and nature of formation of structure, phase composition, defect substructure and properties in surface layers of rail head along the central axis and along the fillet after different terms of operation is necessary for the production of premium-class rails of increased wear resistance and low-temperature reliability including the differentially quenched ones. 
Table 1. Chemical composition of DT350 category rails.

\begin{tabular}{|c|c|c|c|c|c|c|c|c|c|c|c|}
\hline \multirow{2}{*}{ Chemical analysis } & \multicolumn{11}{|c|}{ Content of chemical elements, wt. \% } \\
\hline & $\mathrm{C}$ & $\mathrm{Mn}$ & $\mathrm{Si}$ & $\mathrm{P}$ & $\mathrm{S}$ & $\mathrm{Cr}$ & $\mathrm{Ni}$ & $\mathrm{Cu}$ & $\mathrm{V}$ & $\mathrm{Al}$ & $\mathrm{Ti}$ \\
\hline testing & 0.72 & 0.77 & 0.61 & 0.010 & 0.009 & 0.42 & 0.07 & 0.14 & 0.038 & 0.003 & 0.003 \\
\hline Requirements TU & \multirow{3}{*}{$0.71-0.82$} & \multirow{3}{*}{$0.75-1.25$} & \multirow{3}{*}{$0.25-0.60$} & \multirow{2}{*}{\multicolumn{2}{|c|}{ no more }} & \multirow{3}{*}{$0.20-0.80$} & \multirow{2}{*}{\multicolumn{2}{|c|}{$\Sigma$ no more $0.27 \%$}} & & \multirow{2}{*}{\multicolumn{2}{|c|}{ no more }} \\
\hline 0921-276- & & & & & & & & & $0.03-0.15$ & & \\
\hline 01124323-2012 & & & & 0.020 & 0.020 & & 0.20 & 0.20 & & 0.004 & 0.025 \\
\hline
\end{tabular}

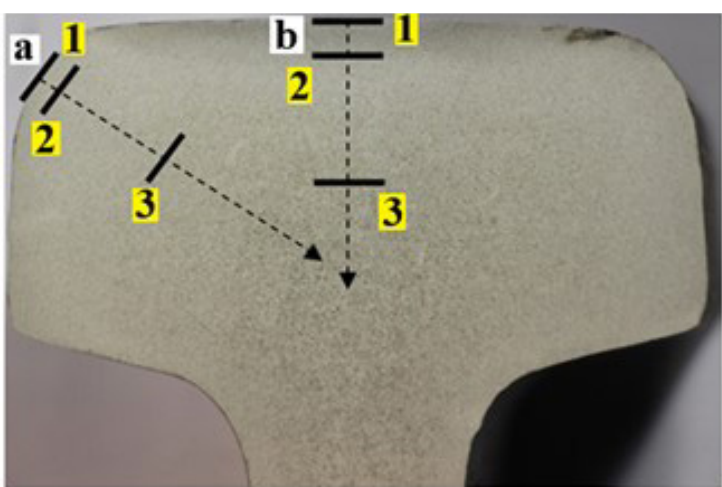

Figure 1. Diagram of sample preparation by methods of transmission electron microscopy. 1-tread surface, 2-layer at $2 \mathrm{~mm}$ from surface, 3-layer at $10 \mathrm{~mm}$ from surface; a) fillet; b) central axis.

A behavior of rail steel at long operation, in its nature, is very close to that of metallic materials at severe (megaplastic, MPD) deformation ${ }^{5-10}$. The general mechanisms of structural formation and evolution at megaplastic deformation of perlite steel are the following: formation of nanometer grains of ferrite, deformation-induced decay of cementite plates and subsequent formation of nanodimensional cementite on dislocations and boundaries of ferrite nanograins. This is due to migration of carbon atoms preferentially along dislocation nuclei.

The research is concerned with the search for regularities of formation of gradient structural phase state in rail steel of pearlite class subjected to severe plastic deformation by extremely long operation on railway.

\section{Material and Methods}

The materials under study were the differentiatedly quenched by compressed air 100-meter rails R65 of DT350 category (Russian Standard P 51685-2013) removed from railway on Experimental testing ground in Shcherbinka town after the passed tonnage of $1411 \mathrm{mln}$. tons brutto. In chemical composition, the metal of rail specimen meets the requirements of technical specifications TU 0921-27601124323-2012 for rails of DT350 category that follows from the results shown in Table 1.

The metal microstructure was studied on metallographic sections cut from the upper part of head (fillet) after etching in $4 \%$ alcohol solution of nitric acid. The studies of steel structure were carried out using the methods of optical microscopy (device Olympus GX51), scanning electron microscopy (device MIRA 3 Tescan) and transmission electron diffraction microscopy (device EM-125) ${ }^{20-23}$. The average grain size was determined by randomly thrown secant method using 200 measurements. The relative content of structural constituents of rail metal was determined by planimetry methods according to images obtained using transmission electron microscopy. The subjects of research for transmission electron microscopy (foils 150-200 nm thick) were manufactured by the method of electrolytical thinning of plates located near the surface and at a distance of $2 \mathrm{~mm}$ and $10 \mathrm{~mm}$ from the surface (Russian Standard P 51685-2013), cut out by the methods of electric spark erosion of metal along fillet radius (Figure 1).

\section{Results and Discussion}

On unetched metallographic sections prepared from head tread surface by the methods of optical microscopy the single fine continuity violations to a depth of $30 \mu \mathrm{m}$ (Figure 2a) are revealed. The depth of deformation from tread surface is insignificant and is less than $35 \mu \mathrm{m}$ (Figure 2b). It is established that microhardness at the depth $2 \mathrm{~mm}$ amounts to $1481 \mathrm{MPa}$ at depth of $10 \mathrm{~mm}$ it is substantially lower and amounts to $1210 \mathrm{MPa}^{10}$.

It is stated that the rail structure in the layer located at a distance of $10 \mathrm{~mm}$ from the fillet surface is formed by pearlite grains of lamellar morphology (Figure 3a). The regions of 'degenerate pearlite' (Figure 3b) and grains of structure-free ferrite (ferrite grains in volume of which cementite particles are absent) (Figure 3c) are present in negligible quantity.

At a distance of $2.0 \mathrm{~mm}$ from the working surface of fillet the deformed pearlite containing the cementite plates fractured into separate parts displaced relative to each other is added to the above mentioned structural constituents of steel (Figure 4a). Comparison of $3 \mathrm{~b}$ and $4 \mathrm{a}$ Figures shows that in structure of fractured pearlite the directionality of cementite plates characteristic of lamellar pearlite is preserved. In the structure of degenerate pearlite grains the cementite particles have a rounded shape or the shape of short plates. Process of lamellar pearlite transformation is carried out by cutting the cementite plates and dissolving them. The first process is accompanied by a change in size of carbide particles and their morphology. The second process is carried out by escape of carbon atoms from crystal lattice of cementite on dislocations with subsequent precipitation of nanosized particles of carbide phase on subboundaries and on dislocations ${ }^{5-7,11,13}$. In the surface layer of the fillet the structure called by us 'ferrite-carbide mixture' is formed in addition to the previously mentioned ones (Figure $4 \mathrm{~b}$ ).

The characteristic feature of the structure is a nanodimensional range of grains, subgrains and particles of the carbide phase forming it. The size of grains and subgrains forming the type of structure varies in the limits of 40-70 nm (Figure 5a). The size of carbide phase particles 


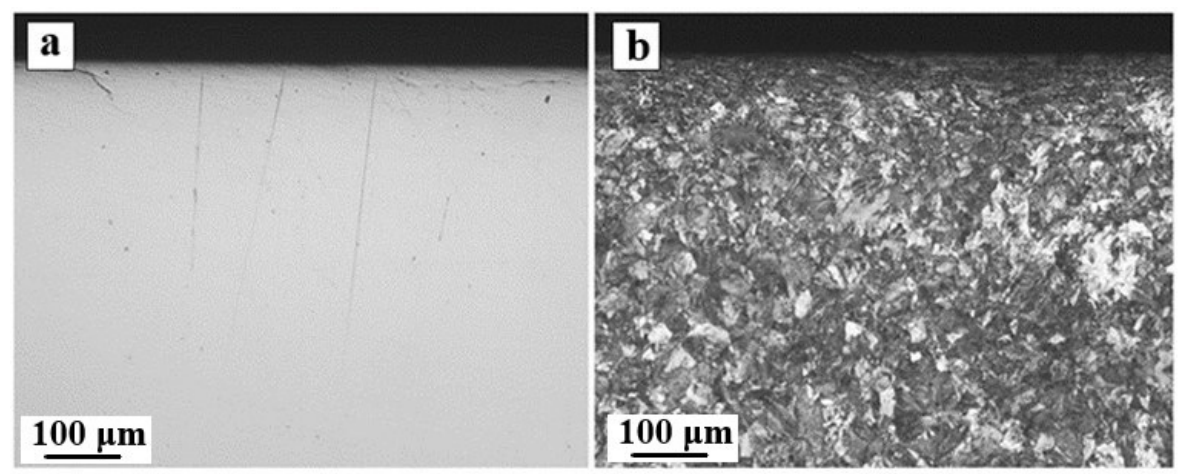

Figure 2. Structure of rail tread surface; $a$ - unetched metallographic section; $b$ - etched metallographic section.
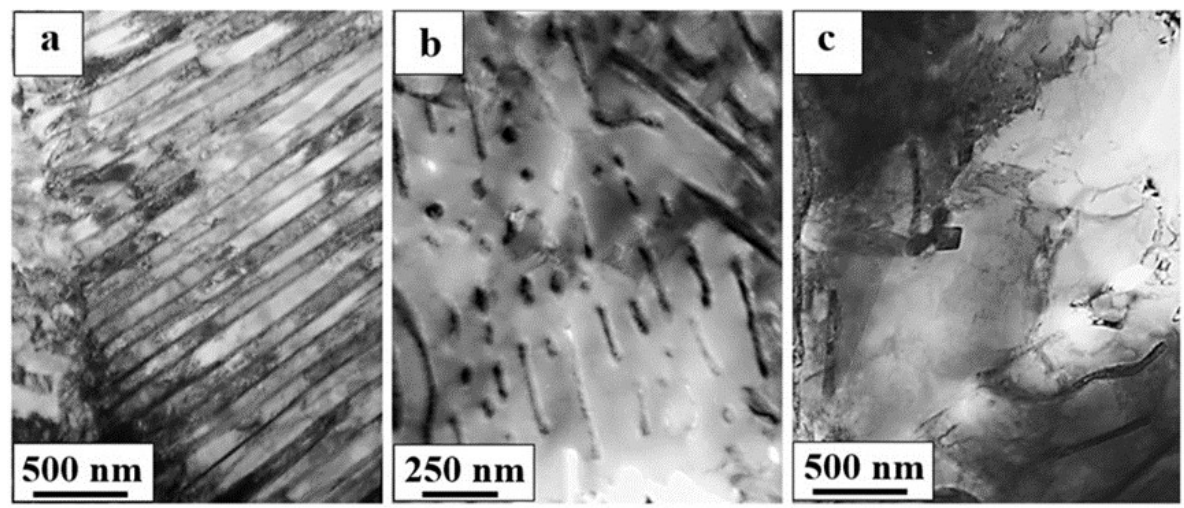

Figure 3. Electron microscopic images of rail structure in the layer located at a depth of $10 \mathrm{~mm}$; $\mathrm{a}$ - lamellar pearlite; $\mathrm{b}$ - degenerate pearlite; $\mathrm{c}$ - structure-free ferrite.
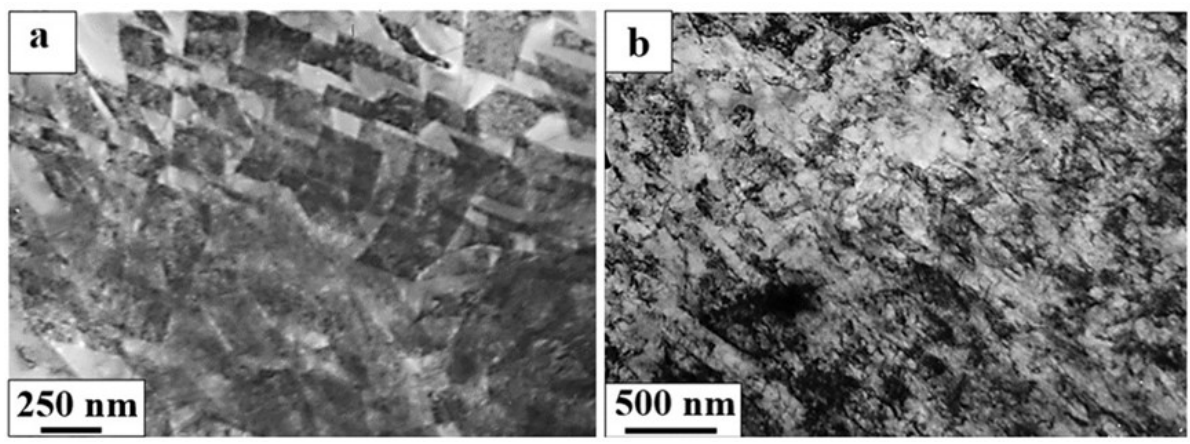

Figure 4. Structure of rail metal; a - fractured lamellar pearlite; b - ferrite-carbide mixture; a - layer at a depth of 2 mm; b - surface layer of fillet.
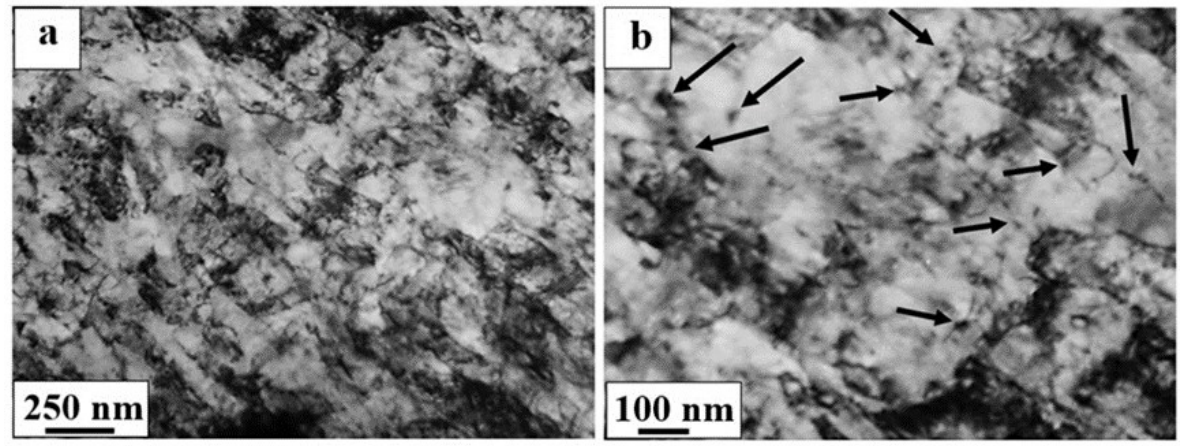

Figure 5. Electron microscopic images of 'ferrite-carbide mixture' structure of surface layer. Arrows indicate in (b) the particles of carbide phase. 
located along the boundaries of grains and subgrains varies in the limits of 8-20 nm (Figure 5b).

The relative content of structural constituents of rail metal varies according to Figure 6. It is clearly seen that long operation of rails is accompanied by the formation of gradient of structural constituents consisting in the regular decrease

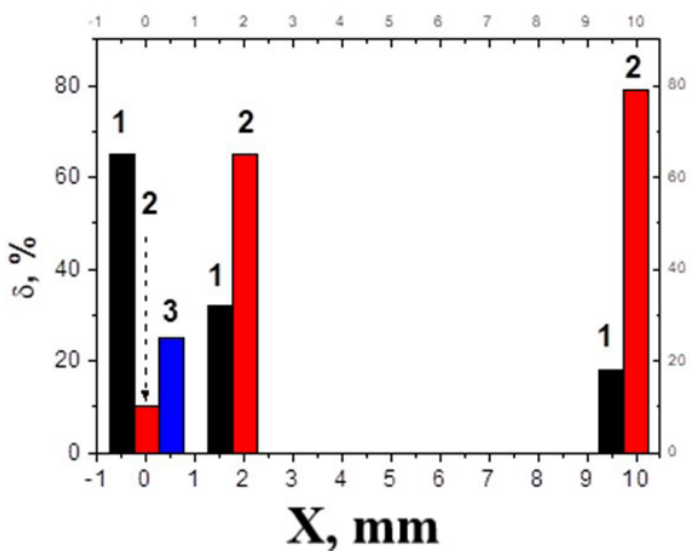

Figure 6. Diagram of relative content of rail structural constituents; 1 - degenerate pearlite + fractured pearlite; 2 - lamellar pearlite; 3 - ferrite-carbide mixture.

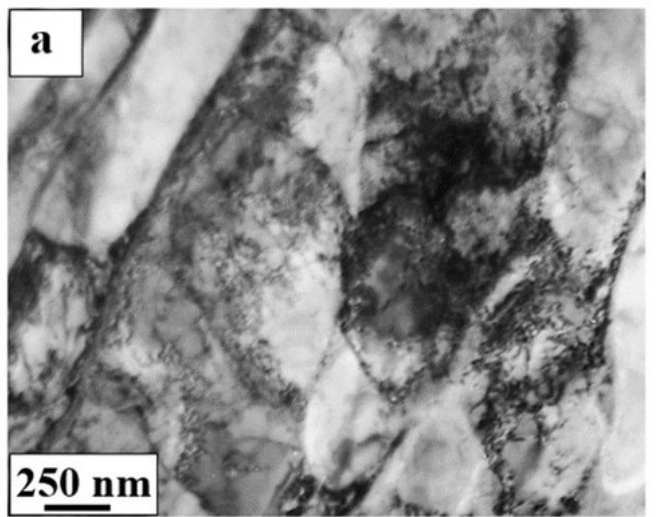

in the relative content of the material with lamellar pearlite structure and the increase in relative content of material with structure of fractured pearlite and ferrite - carbide mixture as the fillet surface is approached.

It has been detected by the method of transmission electron microscopy that a dislocation substructure (Figure 7a) is present in the ferrite constituent of pearlite colonies and grains of structurally free ferrite. Following the classification given $\mathrm{in}^{24,25}$ the dislocations form tangles and nets or are distributed chaotically. The results presented in Figure $7 \mathrm{~b}$, testify that the scalar dislocation density of rail increases as the fillet surface is approached. This is most noticeable in the structure of lamellar pearlite in comparison with the structure of degenerate and fracture pearlite.

The long operation of rails is accompanied by the formation of internal stress fields in steel. In studying the steel structure by the methods of transmission electron microscopy a presence of stress fields in the material shows itself in the appearance of bend extinction contours ${ }^{23}$ on electron microscopic images indicating a curvature-torsion of crystal lattice of this foil's part (Figure 8a).

The bending of a crystal lattice in metals and alloys, including steels (curvature - torsion of crystal lattice) may be of several types ${ }^{26}$. Firstly, a truly elastic bending, being created by stress fields accumulated from the incompatibility

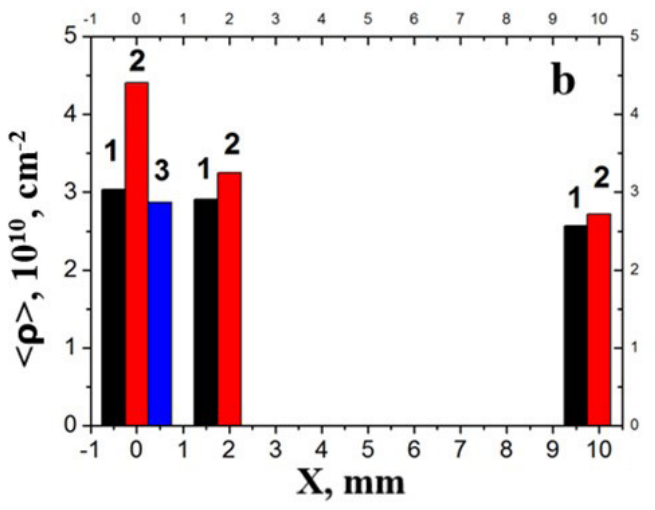

Figure 7. Dislocation substructure of rails observed in the layer at a depth of $10 \mathrm{~mm}$ from fillet surface (a); b - diagram of scalar dislocation density gradient (X - distance from working fillet surface); 1 - degenerate pearlite + fractured pearlite; 2 - lamellar pearlite; 3 - ferrite-carbide mixture.
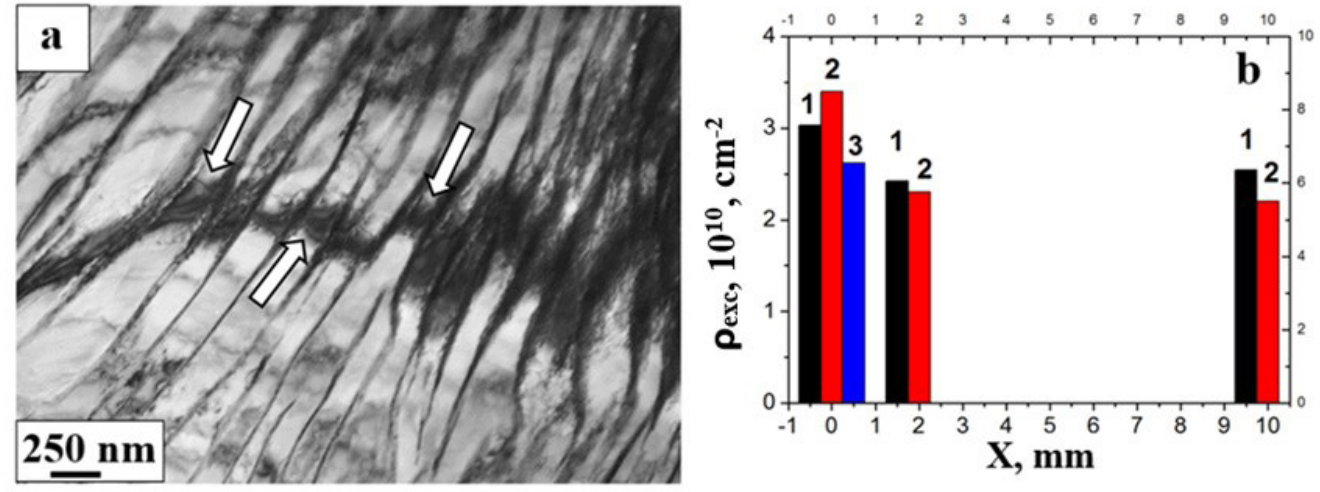

Figure 8. Electron microscopic image of rail structure in the layer located at a distance of $10 \mathrm{~mm}$ from fillet surface (a); b - diagram of gradient of excessive dislocation density (X - distance from working fillet surface); 1 - degenerate pearlite + fractured pearlite; 2 - lamellar pearlite; 3 - ferrite-carbide mixture. Arrows indicate in (a) the bend extinction contour. 


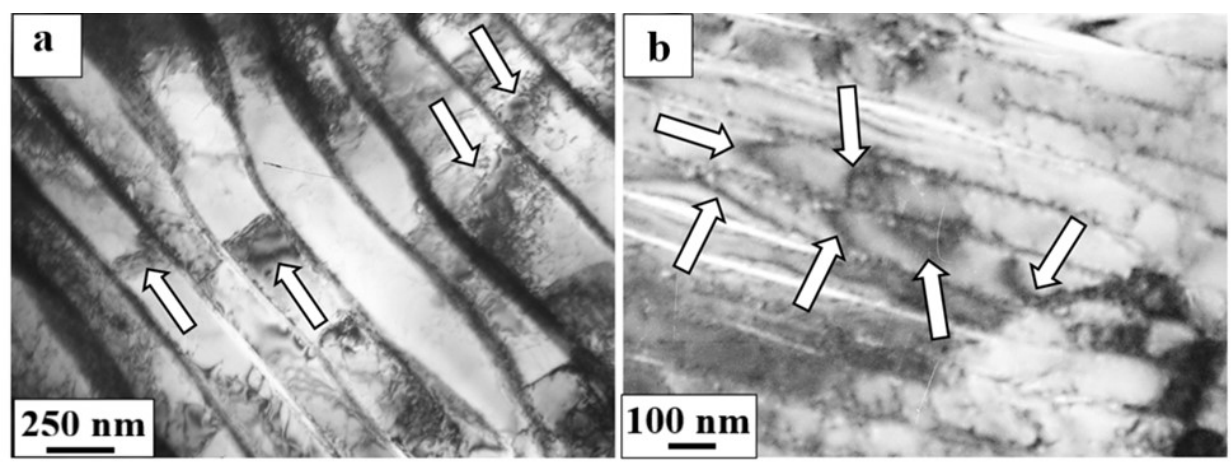

Figure 9. Electron microscopic images of extinction contours (indicated by arrows).

of deformation, for example, grains of polycrystal, colonies of lamellar pearlite or plastic material with non-deformable particles. The sources of stress fields that arise mainly under inhomogeneous deformation of a material, in this case, are boundary junctions and grain boundaries of polycrystals, dispersion -deformable particle/matrix interfaces, in some cases - cracks. Secondly, a plastic bending, if it is created by dislocation charges that is the excessive dislocation density localized in some material bulk. Thirdly, an elastoplastic bending, when both sources of stresses are present in a material.

The analysis technique of internal stress fields based on the behavior of bend extinction contours at inclination of a foil in a microscope column was developed and tested, for the first time, on different materials in papers ${ }^{27,28}$. The estimation procedure of the internal stress field value is reduced to the determination of gradient of curvature-torsion of crystal lattice $\chi$ :

$\chi=\frac{\partial \varphi}{\partial \lambda}=\frac{0.017}{h}$

where $h$ is - transverse dimensions of bend extinction contour.

The value of excessive dislocation density $\rho \pm$ is connected with the gradient of curvature-torsion of crystal lattice $\chi$ through Burgers vector of dislocations b:

$\rho_{ \pm}=\frac{1}{b} \cdot \frac{\partial \varphi}{\partial \lambda}$

Thus, having determined experimentally the transverse dimensions of bend extinction contour in this or that structural constituent of steel it is possible to estimate the value of excessive dislocation density.

When analyzing the results presented in Figure 8b, it can be noted that the largest magnitudes of excessive dislocation density values are reached in the structure of lamellar pearlite, the smallest - in the structure of ferrite-carbide mixture. With the distance from fillet surface the value of excessive dislocation density decreases that is indicative of the decrease in the amplitude of internal stress fields of rail metal.

It is established that a localization scale of internal stress fields of rail material, in a regular way, depends on a distance from the fillet surface. It is found that in the steel layer located at a depth of $\approx 10 \mathrm{~mm}$ the internal stress fields are localized in the bulk of pearlite colony; the sources of stress fields are the interfaces of colonies and grains of pearlite (Figure 8a).
In the layer located at a distance of $\approx 2 \mathrm{~mm}$ from fillet surface the extinction contours are localized in the bulk of several plates of ferrite (Figure 9a). In the layer forming the fillet surface the extinction contours are localized mainly in the bulk of separate plates of ferrite (Figure 9b). It means that the deformation effect taking place at long operation of rails results in the volume gradient of localization internal stress fields of rail metal and therefore, the significant increase in a quantity of stress concentrators that, in turn, will contribute to the increase in the level of embrittlement and operation failure of rails.

\section{Conclusion}

It has been established that the rail structure after long operation in the layer located at a distance of $10 \mathrm{~mm}$ from the fillet surface is formed by pearlite grains of lamellar morphology, regions of 'degenerate pearlite' and grains of structurally free ferrite (ferrite grains in whose volume the cementite particles are absent). It has been shown that a long operation of rails is accompanied by the formation of structural constituents' gradient consisting in a regular change in the relative content of lamellar pearlite, fractured pearlite and structure of ferrite-carbide mixture in cross-section of rail head. As the fillet surface of rail is approached the relative content of metal bulk with the structure of lamellar pearlite decreases but that with the structure of fractured pearlite and ferrite-carbide mixture increases. A typical feature of the ferrite-carbide mixture structure is a nanodimensional range of grains, subgrains and particles of the carbide phase forming it: the dimension of grains and subgrains forming the type of structure varies in the limits of 40-70 nm; the size of the carbide phase particles located along grain and subgrain boundaries varies in the limits of 8-20 nm. It has been revealed that a long operation of rails is accompanied by the formation of gradient of material defective substructure consisting in a regular increase in the value of scalar and excessive dislocation density. It has been determined that the scale of localization of rail internal stress fields depends in a regular way on the distance from the fillet surface changing from the bulk of pearlite colony, on the whole, at a depth of $\approx 10 \mathrm{~mm}$ to the bulk of separate ferrite plates in a fillet layer. It means that long-term operation results in a substantial increase in quantity of stress concentrators which in turn contributes to embrittlement of the material. 


\section{Acknowledgements}

The research was financially supported by the grant RFBI ( $\left.{ }^{\circ} 19-32-60001\right)$.

\section{References}

1. Kozlov EV, Glezer AM, Gromov VE. Gradient structural phase states in solid. Bulletin of the Russian Academy of Sciences. Physics, 2003;67:1374.

2. Gromov VE, Berupiev VA, Kozlov EV, Petrov VI, Sarychev VD, Dorofeev VV, et al. Gradient structural phase states in rail steel. Moscow: Nedra LTD; 2000.

3. Kozlov EV, Kovalenko VV, Popova NA, Gromov VE, Zhuleikin SG. Gradient structures in pearlite steel. Novokuznetsk: SibSIU; 2004.

4. Ivanisenko YuV, Baumann G, Fekht G, Knote K, Safarov IM, Korznikov AV, et al. Nanostructure and hardness of 'white layer' on surface of railway rails. Physics of Metals and physical Metallurgy. 1997;83:104-11.

5. Gromov VE, Yuriev AB, Morozov KV, Ivanov YF. Microstructure of quenched rails. UK: Cambridge, CISP Ltd; 2016.

6. Ivanisenko Yu, Fecht HJ. Microstructure modification in the surface layers of railway rails and wheels. Steel tech. 2008;3:1923.

7. Ivanisenko Y, Maclaren I, Souvage X, Valiev RZ, Fecht HJ. Shear-induced $\alpha \rightarrow \gamma$ transformation in nanoscale $\mathrm{Fe}-\mathrm{C}$ composite. Acta Mater. 2006;54:1659-69. http://dx.doi.org/10.1016/j. actamat.2005.11.034.

8. Jang-li NJ, Courtois-Manara E, Kormanaeva L, Ganeev AV, Valiev RZ, Kubel C, et al. Tensile properties and work hardening behaviors of ultrafine grained carbon steel and pure iron processed by warm high pressure torsion. Mater Sci Eng A. 2013;581:81-9. http://dx.doi.org/10.1016/j.msea.2013.05.008.

9. Gromov VE, Peregudov OA, Morozov KV, Alsaraeva KV, Semina OA, Ivanov YF. Surface layer structure degradation of rails in prolonged operation. J Surf Invest X-ray, Synchrotron Neutron Tech. 2015;10:76-82.

10. Kormyshev VE, Gromov VE, Ivanov YF, Glezer AM, Yuriev AA, Semin AP, et al. Structural phase states and properties of rails after long-term operation. Mater Lett. 2020;268:127499. http://dx.doi.org/10.1016/j.matlet.2020.127499.

11. Gavriljuk VG. Decomposition of cementite in pearlitic steel due to plastic deformation. Mater Sci Eng A. 2003;345:81-9. http://dx.doi.org/10.1016/S0921-5093(02)00358-1.

12. Li YJ, Chai P, Bochers C, Westerkamp S, Goto S, Raabe D, et al. Atomic- scale mechanisms of deformation-induced cementite decomposition in pearlite. Acta Mater. 2011;59:3965-77. http:// dx.doi.org/10.1016/j.ac-tamat.2011.03.022.

13. Gavriljuk VG. Effect of interlamellar spacing on cementite dissolution during wire drawing of pearlitic steel wires. Scr
Mater. 2001;45:1469-72. http://dx.doi.org/10.1016/S13596462(01)01185-X.

14. Seo J-W, Jun H-K, Kwon S-J, Lee D-H. Rolling contact fatigue and wear of two different rail steels under rolling-sliding contact. Int J Fatigue. 2016;83:184-94. http://dx.doi.org/10.1016/j. ijfatigue.2015.10.012.

15. Lewis R, Christoforou P, Wang WJ, Beagles A, Burstow M, Lewis SR. Investigation of the influence of rail hardness on the wear of rail and wheel materials under dry conditions (ICRI wear mapping project). Wear. 2019;430-431:383-92. http:// dx.doi.org/10.1016/j.wear.2019.05.030.

16. Kalousek J, Fegredo DM, Laufer EE. The wear resistance and worn metallography of pearlite, bainite and tempered martensite rail steel microstructures of hardness. Wear. 1985;105:199-222. http://dx.doi.org/10.1016/0043-1648(85)90068-7.

17. Skrypnyk R, Ekh M, Nielsen JCO, Pålsson BA. Prediction of plastic deformation and wear in railway crossings - Comparing the performance of two rail steel grades. Wear. 2019;428429:302-14. http://dx.doi.org/10.1016/j.wear.2019.03.019.

18. Kim D, Quagliato L, Park D, Kim N. Lifetime prediction of linear slide rails based on surface abrasion and rolling contact fatigue-induced damage. Wear. 2019;420-421:184-94. http:// dx.doi.org/10.1016/j.wear.2018.10.015.

19. Huang YB, Shi LB, Zhao XJ, Cai ZB, Liu QY, Wang WJ. On the formation and damage mechanism of rolling contact fatigue surface cracks of wheel/rail under the dry condition. Wear. 2018;400-401:62-73. http://dx.doi.org/10.1016/j. wear.2017.12.020.

20. Egerton FR. Physical principles of electron microscopy. Basel: Springer International Publishing; 2016.

21. Kumar CSSR. Transmission electron microscopy.characterization of nanomaterials. New York: Springer; 2014.

22. Carter CB, Williams DB. Transmission electron microscopy. Berlin: Springer International Publishing; 2016.

23. Hirsch P, Hovy A, Nickolson R, Pashley DW, Whelan MJ. Electron microscopy of fine crystals. Russia: Mir; 1968.

24. Koneva NA, Kozlov EV. Nature of substructure strengthening. Proceedings of Higher Schools. 1982;8:3-14.

25. Kozlov EV, Starenchenko VA, Koneva NA. Evolution of dislocation substructure and thermodynamics of plastic deformation of metallic materials. Metals (Basel). 1993;5:152-61.

26. Ivanov YF, Gromov VE, Popova NA, Konovalov SV, Koneva NA. Structural phase states and strengthening mechanisms of deformed steel. Novokuznetsk: Poligrafist; 2016.

27. Gromov VE, Kozlov EV, Bazaikin VI, Tsellermaier VY, Ivanov YF, Ignatenko LN, et al. Physics and mechanics of drawing and die stamping. Moscow: Nedra; 1997.

28. Ivanov YuF, Kornet EV, Kozlov EV, Gromov VE. Hardened structural steel: structure and mechanisms of strengthening. Novokuznetsk: SibSIU; 2010. 